\title{
Use of Multimedia Messages via Mobile Phones in the Teaching and Learning of French Vocabulary in Schools
}

\author{
Onasanya, Samuel Adenubi ${ }^{1}$ Ayelaagbe, Sina Opeoluwa ${ }^{2 *}$ and Bello, Anne $\mathrm{O}^{3}$ \\ 1. Department of Educational Technology, Faculty of Education, University of Ilorin, P. M. B. 1515, Ilorin, \\ Nigeria \\ 2. Department of Educational Technology Adeyemi College of Education, Ondo. Ondo State, Nigeria \\ 3. Department of French Language. Federal College of Education, Osiele, Abeokuta, Ogun State, Nigeria
}

\begin{abstract}
Educators and researchers have been looking for ways and means of improving the learning of French Vocabulary in schools using Multimedia Message (MMM) via mobile phones so as to improve the vocabulary level of beginners, (students) of French Language, both in terms of their understanding and memorization of new vocabulary. Therefore, this paper extensively discussed the basic elements, some common text devices found in SMSes and relevance of mobile phones to education. Also, contemporary works on the use of MMM via mobile phones in teaching of French vocabulary were discussed. Subsequently, some French vocabularies that can be learnt through MMM via mobile phones were listed and discussed. Some challenges of using MMM via mobile phone in teaching French vocabulary were $x$-rayed. Conclusions were drawn and recommendations made.
\end{abstract}

Keywords: Multimedia Messages (MMM), mobile phones, Short message services $\quad$ (SMS), French Vocabulary, teaching \& learning

\section{Introduction}

Multimedia Message (MMM) is a standard way to send messages that include multimedia content to and from mobile phones. It extends the core Short Message Service (SMS) capability that allowed exchange of text messages only up to 160 characters in length.

Wikipedia, (2007) opined that multimedia message is very popular in sending photographs from camera-equipped handsets, although it is also popular as a method of delivering news and entertainment content including videos, pictures, text pages, ringtones, graphics, and audio. Multimedia can also simply be a drawing that can be combined with text.

Multimedia Message Service (MMS) makes it possible for mobile users to send these multimedia messages from MMS-enabled handsets to other mobile users and to e-mail users. Also, it makes possible for mobile users to receive multimedia messages from other mobile users, e-mail users and from multimedia enabled application.

The technology opens up a world of opportunities, allowing users to access content from the world's leading providers, using cutting-edge handsets and an advanced multimedia platform. MMS crossed all boundaries and is predicted to be a major boost to the General Packet Radio Service (GPRS) market.

Multimedia Message Service (MMS) has the following characteristics:

-Powerful Adaptation: A mobile phone that supports MMS is an amazingly versatile device. It has the ability to take, edit and send images, empower users in all areas of life, enhancing personal connectivity and efficiency. In the work place, it functions as a powerful tool both for conveyance and response to ideas. During leisure time, it adds a whole new dimension to sharing personal experiences. With phone-to-phone as well as phone-tointeract capacity, MMS can also serve as a virtual/email client stored in the phone for future use. MMS brings the power and freedom of complete communication to your finger tips.

-Tailored for Individuals: Your messages can be sent in words, pictures, the soil animated and high-quality video all these can be sent at once. It also can be used to send a digital post card and augment it with an audio clip of one's voice.

-Made to last: This has been adopted by most network operators and mobile device manufacturers. MMS has been a standard mobile phone feature and the default message mode. MMS supports standard image formats such Moving Picture Experts Group (MPEG) 4, and audio formats such as Motion Picture Experts Group (MP3), Musical Instrument Digital (MID) and Wide Area Network (WAN), (Wikipedia, 2007).

Basic Elements of Multimedia Message Service

National Council of Educational Research and Training (2009) categorizes the elements into three: 
MMM Size:- This was designed to deliver short bursts of data such as numerical pages. To avoid overloading the system with more than the standard forward-and -response operation, the inventors of MMM agreed on a 160 character maximum message size. This may vary depending on the network, phone model and wireless carrier. Some services automatically break any message into chunks of 160 characters or less. Therefore, the user can type and send a long message but delivered as several messages.

MMM Communication: There are no standard rules used while writing an MMM.

\section{Shorts}

MMM has evolved from the shorthand use in internet chat rooms to accommodate the small number of characters allowed as a convenient language for the small keyboard on mobile phones. The purpose of text is to use the fewest number of characters needed to convey a comprehensible message.

\begin{tabular}{lll}
\multicolumn{3}{r}{ Barbara (2010) listed some of the MM } \\
BCFUL - & \multicolumn{2}{c}{ Be careful } \\
$\mathrm{SH}$ & - & Shit happens \\
$\mathrm{HAND}$ & - & \multicolumn{2}{c}{ have a nice day } \\
$4 \mathrm{e}$ & - & forever \\
$\mathrm{J} 4 \mathrm{f}$ & - & just for fun. \\
$\mathrm{Bbb}$ & - & byebye. \\
$\mathrm{Zg} 4 \mathrm{u}$ & - & too good for you \\
$\mathrm{Tt}$ & - & think positive \\
$\mathrm{Cu}$ & - & see you \\
$\mathrm{Lol}$ & - & laughing out loud \\
218 & - & too late
\end{tabular}

\section{Expressing Emoticons through 'smiley'}

Many moods can be expressed through 'smiley' which is also used in online chat rooms. In an SMS, they are replaced by alpha-numeric characters and punctuations. Some of them are as follow:

$\begin{array}{lll}:-) & - & \text { cool } \\ :-0 & - & \text { surprised } \\ :-) & - & \text { wink } \\ : 0 \backslash & - & \text { fear/ embarrassment } \\ :-/ & - & \text { skeptical } \\ :-( & - & \text { too bad } \\ \text { @ }- \text {-z } & - & \text { a rose } \\ :-\mathrm{X} & - & \text { kiss } \\ :-\mathrm{P} & - & \text { put out your tongue } \\ (--) \text { zzz } & - \text { sleep } & \\ :-9 & - & \text { tasty }\end{array}$

\section{MMM text input.}

Almost every mobile phone has a key pad which is denominated as $-\mathrm{O}=$ none, $1=$ none, $2=\mathrm{ABC}, 3=\mathrm{DEF}$, 4=GHI, 5=JKL, $6=\mathrm{MNO}, 7=\mathrm{PORS}, 8=\mathrm{TUV}, 9=\mathrm{WXYZ}$. These keypads can also be used to type a message. It provides the following benefits to the user;
(i) Adaptive text features
(ii) Next word prediction.
(iii) Word order preferencing
(iv) Enhanced word completion
(v) User added words.

\section{Common Text Devices found in SMSes and MMM Service.}

(i) Improper Use of Abbreviations: This is the communicators attempt to reduce the key strokes as much as possible. SMS communicators were burdened with tediousness because they had to tap multiple tunes per character, plus that they had to work with a maximum length of 160 characters (Segerstad, 2005). The brevity and speed in texting was manifested in the abbreviation of lexical items. (Thurlaw and Poff, 2011).

Some of the methods employed to shorten words were vowel omissions, acronyms and initializing (Elvis, 2009). Some of the common and traditional abbreviations such as "btw", "pls", "ur", "abt", "den" "fri", "gd", "msg" and "tat". Some of the abbreviations were highly contextual in nature, hence it might not be understood by those who were not in the loop. 
(ii) Homophones:- Grinter and Eldridge (2003), carried out a research and found out that communicators used letters and digits to represent words because they made similar words. Bodomo (2009) also reported similar phonetic-based methods but also included the combination of letters and number homophones such as word "b4".

(iii) Emoticons:- Mobile phones support the insertion of symbols including popular Western emoticons from a list, hence reduce the time and trouble needed to insert-non alphabetic symbols such as (;), (-) and (ग) (Segerstad, 2005).

(iv) Punctuation Errors: This is the omission of apostrophe (c) regularly such in words like "lm", cant", "don't", "wont", "its" and "what" to save time and space.

(v) Capitalization of Errors- This happens regularly for the first letter in the message which was probably due to the default functions of the cellular phone.

(vi) Use of Mixed Language- This involves the use of mother tongues Elvis (2009), also found code mixing among Nigerian testers who mixed English with pidgin, mother tongue and French.

(vii) Colloquialism- This is the informal expressions commonly understood by members of a similar culturing region (Pearson, 2008) Ling (2005) also found that the teens were more indicted to use their dialects than older users in the SMS communication.

\section{Contemporary Works on the Use of Multimedia Messages via Mobile Phones in Teaching French Vocabulary in Schools.}

Over the past few years, studies of vocabulary learning in second foreign language can be divided into two kinds: Vocabulary learning with technology and without technology (Nation, 2011). The researcher address the issue of vocabulary learning more from the perspective of mnemonic devices, learning strategies, the impact of reading, the role of context as well as syntactic and thematic analysis.

Al-seghayer (2001) carried out a research on the studies of vocabulary learning with ComputerMediated Communications (CMC) technologies. His studies revealed a number of encouraging results, which demonstrate that vocabulary learning with computers can be more effective than through the use of traditional learning methods or traditional tools such as dictionaries (Luk \& Ng, 1998) and vocabulary list (Nakata, 2008).

Also, Basoglu and Akdemur (2010) conducted comparative study of vocabulary learning with mobile phones and the paper flash cards. The experimental group used the vocabulary program on the phones to study the target words for six weeks in their extracumcular hours while the control/group worked on the same words on paper flash cards during the same time span. Their findings reveal that vocabulary learning programs running on mobile phones improves students' acquisition of English vocabulary more than traditional vocabulary learning tool, flash cards.

Pecherzewska \& Knot (2007) carried out research concerning mobile learning in research concerning mobile learning in general; the majority of Mobile Assisted Language Learning (MALL) activities appear to make use of mobile phones.

Collins (2005) outlined how MALL activities could be advantageous to the vocabulary learning and quizzes and surveys.

Stockwell (2997) linked the use of mobile phones for vocabulary learning to an intelligent tutor system, learners complete vocabulary activities either via mobile phones or via desktop computers.

Thornton \& Houser (2005) carried out research on (333) Three Hundred and thirty three Japanese students where instructions were sent and received e-mail via their mobile phones in preference to using PCs or PAAs, mobile based e-mail has been used to promote vocabulary learning in Japan.

Cooney \& Keogh (2007) supported the use of mobile phones and IPods to support ISL at secondary level. The aim of their research is to facilitate school-based oral assessment and student's self-assessment, increase students' communicative competence and motivate students to learn Irish with the fun and familiar props of a mobile phone and web-char.

\section{Relevance of Mobile Phone to Education}

Mobile phone learning is a young discipline that is gaining more and more attention because of its promises for education.

Many researchers have pointed out some of the functions of mobile phone to education.

i. Mobile phones have great potential to provide supplementary practices for students outside the school.

ii. Its widespread use and its features and functions such as mobility, reach ability, localization and personalization, mobile phone technology may lead to positive effects in learning environments.

iii. Mobile phones in education settings will help learners be more motivated.

iv. It will assist the learners to overcome the difficulties teachers or parents experience in order to make learners start studying 
v. It enables the learners to use any previous wasted time (on the bus, on their way back and to school) on learning languages (Barbara, 2010; Onasanya S. A., Ayelaagbe S. O., Laleye A. M. 2012)

\section{Some French Vocabularies that can be learnt through MMM via Mobile Phones}

Vocabulary learning is crucially important for French second language learners' fluent communicative ability. As Wilkins (1992) in Zhang H. Song, Wei and Burston Jack (2011) put it, without grammar very little can be conveyed, without vocabulary nothing at all can be conveyed. Harmer (1994) also echoed that, if language structures make up the skeleton of language, then it is vocabulary that provides the vital organs and the vocabulary has been an integral part of the learning process for French language learners.

Generally, vocabulary learning can be categorized into two kinds; Intentional and Incidental.

Intentional vocabulary learning refers to any activity aiming at committing lexical information to memory (Robinson, 2001). It involves investing the necessary mental effort and memorizing the words until learners know their learning (Koren, 1999) this is in contrast to incidental vocabulary learning which refers to vocabulary learning as a byproduct of something else (Gass \& Selinker, 2001) such as reading a passage for comprehension, listening to news of local, national or international events etc.

Family

\begin{tabular}{lllll}
- & aunt & \multicolumn{3}{c}{ Tante } \\
- & brother & - & Frere & \\
- & Cousin (female) & - & \multicolumn{2}{c}{ Cousine } \\
- & Cousin (male) & - & Cousin & \\
- & daughter & & - & Fille \\
- & father & & - & Pere \\
- & grandfather & & - & Grand_pere \\
- & husband & - & mari & \\
- & mother & - & Mere & \\
- & wife & & - & Epouse
\end{tabular}

\section{House}

$\begin{array}{ll}- & \text { a shelf } \\ - & \text { a bed } \\ - & \text { a calculator } \\ - & \text { a chair } \\ - & \text { a computer } \\ - & \text { a door } \\ - & \text { a desk } \\ - & \text { floor } \\ - & \text { lamp } \\ - & \text { oven }\end{array}$

$$
\begin{array}{ll}
\multicolumn{2}{l}{\text { Une étagère }} \\
- & \text { Un lit } \\
- & \text { Une calculatrice } \\
\text { Une chaise } & \\
- & \text { Un ordinateur } \\
\text { Une Porte } & \text { Un bureau } \\
- & \text { etage } \\
- & \text { Une lampe } \\
- & \text { Un four }
\end{array}
$$

\section{Body Parts}

- $\quad$ ankle

- $\quad$ arm

- cheek

- ear

- eye

- face

- foot

- head

- hand

- mouth

$\begin{array}{ll}- & \text { la cheville } \\ - & \text { le bras } \\ - & \text { la joue } \\ - & \text { Une Oreille } \\ - & \text { Un oeil } \\ - & \text { Le visage } \\ - & \text { Le pied } \\ - & \text { La tete } \\ - & \text { la main } \\ \text { La bouche etc. }\end{array}$

Challenges in using Multimedia Message via Mobile Phone in Teaching of French Vocabulary

There are some interesting challenges with multimedia message service. These include the following as enumerated in (Wikipedia 2007).

(i) Content Adaptation: Multimedia content created by one brand of MMS phone may not be entirely compatible with the capabilities of the recipient's MMS phone. In the MMS architecture, the recipient MMSC is responsible for providing for content adaptation (e.g. Image is resizing, audio codec trancoding etc), if this feature is enabled by the mobile network operator. When content adaptation is supported by a network operator, 
its MMS subscribers enjoy compatibility with a larger network of MMS users than would otherwise be available.

(ii) Distribution Lists: Current MMS specifications do not include distribution lists on methods by which large numbers of recipients can be conveniently addressed and particularly by content providers, called valueadded. Service Providers (VASPs) in 3GPP. Most SMSC vendors have adopted File Transfer Protocol (FTP) as an adhoc method by which large distribution lists are transferred to the SMSes prior to being used in a bulkmessaging SMS submission, it is expected that MMSC vendors will also adopt FTP.

iii. Bulk Messaging: The flow of peer-to-peer MMS messaging involves several over-the-air transactions that become inefficient when MMS is used to send messages to large numbers of subscribers, as is typically the case for VASPs. For instance, when one MMS message is submitted to very large recipients, it is possible to receive a delivery report and read-reply report for each and every recipient. Future MMS specification work is likely to optimize and reduce the transactional overhead for the bulk-message case.

iv. Handset Configuration: Unlike SMS, MMS requires a number of hand set parameters to be set. Poor handset configuration is often blamed as the first point of failure for many users. Service settings are sometimes preconfigured on the handset, but mobile operators are now looking at new device management technologies as a means of delivering the necessary setting for data services (MMS, WAP etc) via over-the-air programming (OTA).

v. WAP Push: Few mobile network operators offer direct connectivity to their MMS for content providers. This has resulted in many content providers using WAP push as the only method available to deliver rich content to mobile hand sets. Wireless Application Protocol (WAP) push enables "rich content" to be delivered to a handset by specifying the Uniform Resource Locator (URL) (via binary SMS) of a pre-compiled MMS, hosted on a content provider's web server. The effect is that the receiver who pays WAP perk or minute (as opposed to a flat monthly fee) pays for receiving the MMS, as opposed to only paying for sending one, and also paying a different rate.

\section{Conclusion}

In the drive for better performance of students in using multimedia messages via mobile phones in teaching of French vocabulary in schools, teachers should be more committed in utilizing multimedia messages via mobile phones. This paper dealt with various meanings of multimedia messages, discusses the basic elements, some common text devices found in SMSes and relevance of mobile phones to education were discussed. Also, some of the contemporary works on the use of MMM via mobile phones in the teaching of French vocabulary were x-rayed. French vocabulary and the challenges for using MMM via mobile phones were listed and discussed.

\section{Recommendations}

Finally, the recommendations were offered to assist the interested teachers willing to use multimedia in teaching-learning process in schools.

1. Mobile phones should be used as a complement of traditional vocabulary learning such as use of vocabulary books and dictionaries as well as context-based vocabulary learning

2. Delivery schedules should be worked out together with students.

3. There should not be conflict between teachers work schedules and vocabulary delivery schedules. This can be prevented by the teacher planning ahead to avoid troublesome conflicts or think of other technologies that could support timed message deliver.

4. Multimedia messages should be of quality and be received by the students instantly. This is so because they expect it to happen and are psychologically ready for the messages.

5. Short messaging technology can effectively facilitate vocabulary learning on the strength of the technology's advantages, therefore short message should be sent.

6. The use of mobile phones is necessary in schools but should be monitored so that it may not be abused by the users,

7. Parents should encourage their children by purchasing mobile phones that will be suitable for sending short messages.

\section{References}

[1]. Al-Seghayer, K. (2001). The Effect of Multimedia Annotation Modes on 12 Vocabulary acquisition: A Comparative Study. Language Learning \& Technology, 5(1), 202-232.

[2]. Basoglu, E. B \& Akdemer, O. (2010). A Comparison of Undergraduate Students' English Vocabulary Learning. Using Mobile Phones and Flash Cards. The Turkish Online Journal of Educational Technology, 9(3), 1-7.

[3]. Barbara, B. (2010). Using the Mobile Phone in School: Handling Opportunities and Risks Appropriately. Margaretenstraise, Austrian Institute for Applied Telecommunication (OIAT). 
[4]. Collins, T. (2005). English Class on the Air: Mobile Language Learning with Cell Phones Proceedings of the Fifth/EEE International Conference on Advanced Learning Technologies (ICALT' 05), Retrieved Proceedings/lcalt/2005/2338/00/23380402.pdf.

[5]. Coonezz, G \& Keogh, K. (2007). Use of Mobile Phones for Language Learning and Assessment for Learning. Paper Presented at Milearn 2007. Retrieved from http://www.learnobity.com/files/learnosity-use-of-mobile-phones-for-language-learning-andassessment-for-learning-pdf

[6]. Elvis, F. W. (2009). The Sociolinguistics of Mobile Phone SMS Usage in Cameroon and Nigeria. The International Journal of Language Society and Culture Retrieved from http:ww:educ.utas.edu.au/users/the/JOURNAL/issues/2009/28-3,pdf.

[7]. Gass, S. M \& Selinker, L. (2001) Second Language Acquisition: An Introductory Course Mahwah, NY: Lawrence Erlbaum Associates.

[8]. Koren, S. (1999). Vocabulary Instruction through Hypertext: Are there Advantages over Conventional Methods of Teaching? TESL-EY. 4(1) A-2, 1-18 Retrieve from http:test-eg.org/ej13/93.html.

[9]. Luk, R. W. \& Ng. A. B (1998). Computer-assisted Learning of Chinese Idoms. Journal of Computed Assisted Learning. 14(1).

[10]. Nation, P. (1990). Teaching and Learning Vocabulary. Boston: Heinle \& Heinle.

[11]. Onasanya S. A., Ayelaagbe S. O., Laleye A. M. (2012): Mobile Phones and Adult Education in Nigeria: Prospects and Future Challenges. New Media and Mass Communication. Published by the International Institute for Science, Technology and Education (IISTE) Hong Kong SAR (8)1-6 Downloadable at http://www.iiste.org/Journals/index.php/NMMC/article/view/3775/3824

[12]. Pecherzewska, A. \& Knot, S. (2007). Review of Existing Eu Projects Dedicated to Dystlexia Gaming in Education and MLearning. UR 08 Report to CallDysc Project. June, 2007.

[13]. Pearson, J. Nelson, P. Titsworth, S. \& Harter, I. (2008). Human Communication (3rd ed)- Boaston: MeGraw-Hill.

[14]. Robinson, P. (2001). Cognition and Second Language Instruction. Cambridge, UK: Cambridge University Press.

[15]. Segerstail, U. L. (2005). Language in SMS: A Social Linguistic View.

[16]. Stockwell, G. (2007). Vocabulary on the Mwe; Investigating an Intelligent Mobile-based Vocabulary Tutor. Computer Assisted Language Learning, 20(4), 365-383.

[17]. Thornton, P. \& Houser, C. (2005). Using Mobile Phones in English Education in Japan. Journal of Computer Assisted Learning. 21(3), 217-228.

[18]. Thurlow, C. \& Poff, M. (2011). Text Messaging. Handbook of the Pragmatics of CMC Berlin \& New Yonki Monton de Gruysters.

[19]. Wikipedia (2007). Text Messaging, the Free Encyclopedia. Retrieved from-http://en.wikipedia.org/wiki/text-messaging. 